CLINICAL STUDY

\title{
Differential developmental expression of transcription factors GATA-4 and GATA-6, their cofactor FOG-2 and downstream target genes in testicular carcinoma in situ and germ cell tumors
}

\author{
Jonna Salonen ${ }^{1,2}$, Ewa Rajpert-De Meyts ${ }^{3}$, Susanna Mannisto ${ }^{1}$, John E Nielsen ${ }^{3}$, Niels Graem ${ }^{4}$, Jorma Toppari ${ }^{5}$ \\ and Markku Heikinheimo ${ }^{1,6}$ \\ ${ }^{1}$ Institute of Biomedicine, Paediatric Research Center, Children's Hospital, University of Helsinki, Biomedicum Helsinki, PO Box 20, SF-00014 Helsinki, \\ Finland, ${ }^{2}$ Program for Women's Health, Biomedicum Helsinki, SF-OOO14 Helsinki, Finland, ${ }^{3}$ University Department of Growth and Reproduction, \\ Rigshospitalet, Copenhagen, DK-2100 Denmark, ${ }^{4}$ Department of Pathology, Rigshospitalet, Copenhagen, DK-2100 Denmark, ${ }^{5}$ Departments of Physiology \\ and Paediatrics, University of Turku, Turku, 20520 Finland and ${ }^{6}$ Department of Pediatrics, Washington University School of Medicine, St Louis, 63310 \\ Missouri, USA
}

(Correspondence should be addressed to M Heikinheimo who is now at Children's Hospital, University of Helsinki, PO Box 22, SF-OOO14 Helsinki, Finland; Email: markku.heikinheimo@helsinki.fi)

\begin{abstract}
Objective: Testicular germ cell cancer is the most common malignancy among young males. The preinvasive precursor, carcinoma in situ testis (CIS), presumably originates from arrested and transformed fetal gonocytes. Given that GATA transcription factors have essential roles in embryonic and testicular development, we explored the expression of GATA-4, GATA-6, cofactor friend of GATA (FOG)-2, and downstream target genes during human testis development and addressed the question whether changes in this pathway may contribute to germ cell neoplasms.

Methods: Fetal testis, testicular CIS, and overt tumor samples were analyzed by immunohistochemistry for GATA-4, GATA-6, FOG-2, steroidogenic factor 1 (NR5A1/SF1), anti-Müllerian hormone/Müllerianinhibiting substance $(A M H)$, and inhibin- $\alpha(I N H \alpha)$.

Results: GATA-4 was not expressed in normal germ cells, except for a subset of gonocytes at the 15 th gestational week. The CIS cells expressed GATA-4 and GATA-6 heterogeneously, whereas most of the CIS cells expressed GATA-4 cofactor FOG-2. GATA target gene SF-1 was expressed heterogeneously in CIS cells, whereas INH $\alpha$ and AMH were mostly negative. Seminomas and yolk sac tumors were positive for GATA-4 and GATA-6, but mostly negative for FOG-2 and the GATA target genes. In contrast, pluripotent embryonal carcinomas and choriocarcinomas were GATA-4 and GATA- 6 negative.

Conclusions: Differential expression of the GATA-4 target genes suggested cell-specific functions of GATA- 4 in the germ and somatic cells. The GATA-4 expression in early fetal gonocytes, CIS, and seminoma cells but the absence in more mature germ cells is consistent with the early fetal origin of CIS cells and suggests that GATA-4 is involved in early germ cell differentiation.
\end{abstract}

European Journal of Endocrinology 162 625-631

\section{Introduction}

Six GATA factors (GATA-1 to GATA-6) are evolutionary conserved transcription factors that bind the consensus motif WGATAR in the regulatory regions of various genes. GATA-4 has important roles in the fetal development of the gonads (1-4). Several GATA-4 target genes are essential in gonadal differentiation steroidogenic factor 1 (SF1, SRY, SOX9) and hormone regulation anti-Müllerian hormone $(A M H$, inhibin- $\alpha$ $(I N H-\alpha)$ ) (3, 5-8). During fetal testis development, GATA- 4 and GATA- 6 are expressed in mouse and human Sertoli and Leydig cells $(9,10)$. An essential GATA-4 co-factor, friend of GATA (FOG)-2 is also expressed in murine Sertoli and Leydig cells $(11,12)$, and it is known that FOG-2 interaction is required for proper GATA-4 function in the testis. Accordingly, in mice homozygous for a Gata4 variant that cannot interact with FOG-2 or in mice homozygous for Fog 2 null mutant, Sertoli cell differentiation is blocked resulting in abnormal testis morphogenesis presumably due to an abnormal SRY expression (5). No human mutations in these factors leading to abnormal testicular phenotype have been described so far.

The expression of GATA-4 in germ cells has not been satisfactorily demonstrated, except for one study suggesting its presence in fetal gonocytes (9). Testicular germ cell tumors (TGCTs) provide a unique model to study pathways of early germ cell differentiation and somatic transformation. TGCTs that occur in young adults develop from a common precursor, the carcinoma in situ (CIS) cell (13). CIS cells are phenotypically 
nearly indistinguishable from fetal gonocytes and most likely originate from these cells (14). After puberty, CIS transforms into overt tumors divided into two main histological subtypes, seminomas and non-seminomas. Seminomas retain germ cell features and have a very similar gene expression profile to CIS cells, whereas nonseminomas no longer express germ cell-specific genes and may contain several types of somatic tissues (15).

In this study, we exploited above-described features of TGCTs to study the possible role of GATA-4 transcription factor in early germ cells and during malignant transformation. For this purpose, we analysed GATA-4 expression in testicular CIS and overt TGCT, as well as in human fetal testis. In addition, we investigated GATA-4's essential co-factor FOG-2, the closely related family member GATA-6, and downstream target genes SF1, $A M H /$ Müllerian-inhibiting substance (MIS), and INH $\alpha$ in the same tissue samples.

\section{Tissue samples and methods}

\section{Tissue samples}

The Regional Committee for Medical Research Ethics in Denmark has approved the use of anonymized human tissue samples for gene expression studies.

The ten normal fetal (gestational weeks 15-41) testis samples were obtained from tissue archives of the Department of Pathology at the Rigshospitalet, Copenhagen, Denmark. Tissues were stored after autopsy of material from induced or spontaneous abortions and stillbirths, mainly due to placental or maternal problems. The fetal age was estimated from the date of the last menstrual bleeding, supported by the foot length of the fetus. Specimens of testicular tumors and the adjacent tissue, which usually contains CIS, were obtained after therapeutic orchidectomy. The fetal tissue samples were fixed in neutral buffered formalin $(4 \%)$, whereas adult tissues were fixed either in buffered formalin or $4 \%$ paraformaldehyde, embedded in paraffin, and sectioned. In total, 10 CIS and 19 tumor samples (six seminomas and 13 non-seminomas) were analyzed using immunohistochemistry.

\section{Immunohistochemistry}

The antibodies used for immunohistochemistry were purchased from Santa Cruz Biotechnology (Santa Cruz, CA, USA): AP- $\gamma \gamma$ (Catalogue no. sc-12762, 1:200), FOG-2 (sc-10755, 1:1000), GATA-4 (sc-1237, dilution 1:200), GATA-6 (sc-9055, 1:500), OCT4 (POU5F1) (C-20, sc-8629, 1:250); from Affinity BioReagents (Golden, CO, USA): SF-1 (PA124565, 1:2000); from Serotec (Oxford, UK): inhibin- $\alpha$ (MCA951s, 1:500); and from Dako (Glostrup, Denmark): $\alpha$-1-fetoprotein (AFP) (A008, 1:600), human chorionic gonadotropin (A0231, 1:1500). The MAB to AMH (MIS) was a gift from Dr R Cate (Biogen, Cambridge, MA, USA).
The paraffin-embedded tissue sections were deparaffinized and rehydrated using descending concentrations of ethanol. Antigen retrieval was performed by incubating the slides in $0.1 \mathrm{M}$ citric acid (pH 8.0) at $\sim 100{ }^{\circ} \mathrm{C}$ for $20 \mathrm{~min}$. Endogenous peroxidase activity was blocked with $3 \% \mathrm{H}_{2} \mathrm{O}_{2}$ in water for $5 \mathrm{~min}$. The incubation with primary antibody was carried overnight at $4{ }^{\circ} \mathrm{C}$. An avidin-biotin immunoperoxidase system was used to visualize bound antibody (Vectastain Elite ABC Kit, Vector Laboratories, Burlingame, CA, USA), with 3,3'-diaminobenzidine (Sigma) or aminoethyl carbazole (Zymed, San Francisco, CA, USA) as chromogens. The sections were counterstained with hematoxylin. In negative control experiments, PBS replaced the primary antibody.

The stained sections were analyzed under a light microscope. Scoring of the antigens was based on the staining intensity of at least $10 \%$ of the tumor cells, divided into three categories: + , positive staining; $+/-$, heterogeneous staining; and - , no staining.

\section{Results}

\section{GATA-4 is expressed in early fetal gonocytes}

The expression of GATA- 4 during fetal testis development was examined using a series of samples listed in Table 1. Gonocytes were identified by their morphology and staining for $\mathrm{AP}-2 \gamma$, which in the fetal testis is a gonocytes-specific marker (16). In early fetal testis (15th gestational week), a subpopulation of gonocytes expressed GATA-4 (Fig. 1, Table 1). After the 17th gestational week, GATA-4 was no longer detectable in germ cells. In contrast, GATA-4, FOG-2, SF1, and INH $\alpha$ were expressed in fetal somatic cells (Sertoli and Leydig cells) in almost all fetal samples (weeks 15-41). GATA-6 was expressed only in a subpopulation of early fetal Sertoli cells. AMH was expressed in fetal Sertoli cells of all fetal ages but not in germ cells.

In the adult testis, GATA-4 was positive in Sertoli and Leydig cells, as previously described (9). Normal germ cells were negative for GATA-4, except for a heterogeneous staining of acrosomes in subset of spermatids, which was apparently unspecific. GATA-6, FOG-2, SF1, and INH $\alpha$ were mostly negative in germ cells, whereas Sertoli and Leydig cells expressed GATA-6, FOG-2, SF1, and $\mathrm{INH} \alpha$, as described earlier $(10,12,17)$.

\section{Differential expression of GATA-4 and its target genes in CIS cells and overt germ cell tumors}

Most of the CIS samples expressed GATA-4 (Fig. 2). GATA-4 expression in CIS cells was heterogeneous, positive cells ranging from 24 to $93 \%$ of all CIS cells in a given tubule, and with variable intensity. In CIS cells, the staining was localized into the nucleus and 
Table 1 Expression of GATA-4, GATA-6, and co-factor friend of GATA (FOG)-2 and their target genes in fetal germ and Sertoli cells, carcinoma in situ testis (CIS), and testicular tumors.

\begin{tabular}{|c|c|c|c|c|c|c|c|c|c|c|c|c|c|}
\hline \multirow{2}{*}{$\begin{array}{l}\text { Tissue } \\
\text { type }\end{array}$} & \multirow{2}{*}{$\begin{array}{c}\text { Fetal } \\
\text { age } \\
\text { (weeks) }\end{array}$} & \multicolumn{2}{|c|}{ GATA-4 } & \multicolumn{2}{|c|}{ FOG-2 } & \multicolumn{2}{|c|}{ GATA-6 } & \multicolumn{2}{|c|}{ AMH/MIS } & \multicolumn{2}{|c|}{ SF-1 } & \multicolumn{2}{|c|}{ INH $\alpha$} \\
\hline & & Gc & Sert & Gc & Sert & Gc & Sert & Gc & Sert & Gc & Sert & $\mathrm{Gc}$ & Sert \\
\hline \multirow[t]{10}{*}{ Fetal testis } & 15 & $+1-$ & + & - & $+1-$ & - & $+1-$ & - & + & - & $+1-$ & + & + \\
\hline & 15 & $+1-$ & + & - & - & - & + & - & - & - & $+1-$ & + & + \\
\hline & 17 & - & + & - & + & - & - & - & + & - & + & - & + \\
\hline & 18 & - & $+1-$ & + & $+1-$ & - & - & - & + & - & - & - & + \\
\hline & 18 & - & + & - & + & - & + & - & + & - & + & - & + \\
\hline & 20 & - & + & - & + & - & + & - & + & - & + & - & + \\
\hline & 20 & - & + & + & + & - & + & - & + & - & + & + & + \\
\hline & 24 & - & - & - & + & - & - & - & + & - & - & - & - \\
\hline & 39 & - & + & - & + & - & - & - & + & - & - & - & + \\
\hline & 41 & - & + & + & + & - & - & - & + & - & + & - & + \\
\hline & & \multicolumn{2}{|c|}{ GATA-4 } & \multicolumn{2}{|c|}{ FOG-2 } & \multicolumn{2}{|c|}{ GATA-6 } & \multicolumn{2}{|c|}{ AMH/MIS } & \multicolumn{2}{|c|}{ SF-1 } & \multicolumn{2}{|c|}{$\mathrm{INH} \alpha$} \\
\hline $\begin{array}{l}\text { CIS/adjacent } \\
\text { tumour }\end{array}$ & $\begin{array}{c}\text { Age } \\
\text { (years) }\end{array}$ & CIS & Sert & CIS & Sert & CIS & Sert & CIS & Sert & CIS & Sert & CIS & Sert \\
\hline CIS/NSE & 28 & + & + & + & - & + & + & - & $+^{a}$ & + & + & - & + \\
\hline $\mathrm{CIS} / \mathrm{NSE}+\mathrm{SE}$ & 27 & + & + & $+1-$ & + & $+1-$ & + & - & - & + & $+1-$ & - & + \\
\hline CIS/SE & 35 & $+1-$ & + & + & + & + & $+1-$ & - & $+^{a}$ & + & $+1-$ & + & + \\
\hline CIS/SE & 29 & $+1-$ & + & + & + & $+1-$ & $+1-$ & - & $+^{a}$ & $+1-$ & + & + & + \\
\hline CIS/SE & 32 & $+1-$ & + & + & + & $+1-$ & + & - & - & $+1-$ & $+1-$ & - & + \\
\hline CIS/NSE & 20 & $+1-$ & + & + & + & $+1-$ & + & - & - & - & + & $+1-$ & + \\
\hline CIS/NSE & 32 & $+1-$ & + & + & + & $+1-$ & + & - & - & $+1-$ & $+1-$ & - & + \\
\hline CIS/NSE & 28 & $+1-$ & + & + & + & - & + & - & - & $+1-$ & + & - & + \\
\hline CIS/NSE & 23 & $+1-$ & + & $+1-$ & + & $+1-$ & + & - & $+^{a}$ & $+1-$ & + & - & + \\
\hline CIS & 27 & $+1-$ & + & - & + & - & + & - & - & $+1-$ & + & - & + \\
\hline \multicolumn{2}{|l|}{ Overt tumour } & \multicolumn{2}{|c|}{ GATA-4 } & & G-2 & & A-6 & AN & /MIS & & $F-1$ & & \\
\hline SE & 22 & & $1-$ & & $1-$ & & $1-$ & & - & & - & & \\
\hline SE & 29 & & $1-$ & & $1-$ & & - & & - & & - & & \\
\hline SE & 29 & & $1-$ & & - & & + & & - & & + & & \\
\hline SE & 33 & & $1-$ & & - & & $1-$ & & - & & - & & \\
\hline SE & 43 & & $1-$ & & - & & $1-$ & & - & & - & & \\
\hline SE & 37 & & $1-$ & & - & & - & & - & & - & & \\
\hline EC & 32 & & - & & - & & - & & - & & - & & \\
\hline EC & 34 & & - & & - & & - & & - & & - & & \\
\hline EC & 32 & & - & & - & & - & & - & & - & & \\
\hline EC & 35 & & - & & - & & - & & - & & - & & \\
\hline EC & 26 & & - & & - & & - & & - & & - & & \\
\hline EC & 31 & & - & & - & & - & & - & & - & & \\
\hline EC & 27 & & - & & - & & - & & - & & - & & \\
\hline EC & 21 & & - & & - & & - & & - & & - & & \\
\hline EC & 38 & & - & & - & & - & & - & & - & & \\
\hline YST & 35 & & $1-$ & & - & & $1-$ & & - & & $+1-$ & & \\
\hline YST & 26 & & $1-$ & & $-1-$ & & $1-$ & & - & & $+1-$ & & \\
\hline YST & 27 & & t & & $-1-$ & & + & & - & & $+1-$ & & \\
\hline YST & 30 & & t & & - & & + & & - & & $+1-$ & & \\
\hline YST & 21 & & + & & - & & + & & - & & $+1-$ & & \\
\hline $\mathrm{CHC}$ & 26 & & - & & - & & - & & - & & - & & \\
\hline $\mathrm{CHC}$ & 31 & & - & & - & & - & & - & & - & & \\
\hline $\mathrm{CHC}$ & 36 & & - & & - & & - & & - & & - & & \\
\hline TE & 35 & & $1-$ & & $-1-$ & & - & & - & & - & & \\
\hline TE & 27 & & $1-$ & & $-1-$ & & - & & - & & - & & \\
\hline TE & 38 & & - & & - & & $1-$ & & - & & $+1-$ & & \\
\hline
\end{tabular}

Gc, germ cell; Sert, Sertoli cell; CIS, testicular carcinoma in situ; AMH/MIS, Anti-Müllerian hormone/Müllerian-inhibiting substance; SF-1, steroidogenic factor 1; INH- $\alpha$, inhibin- $\alpha$; SE, seminoma; NSE, non-seminoma; EC, embryonal carcinoma; YST, yolk sac tumor; CHC, choriocarcinoma; TE, teratoma. NSE tumors were composed of EC, YST, CHC, and TE components.

${ }^{\mathrm{a}} \mathrm{AMH}$ positivity was observed only in visibly undifferentiated Sertoli cells in a few tubules. 

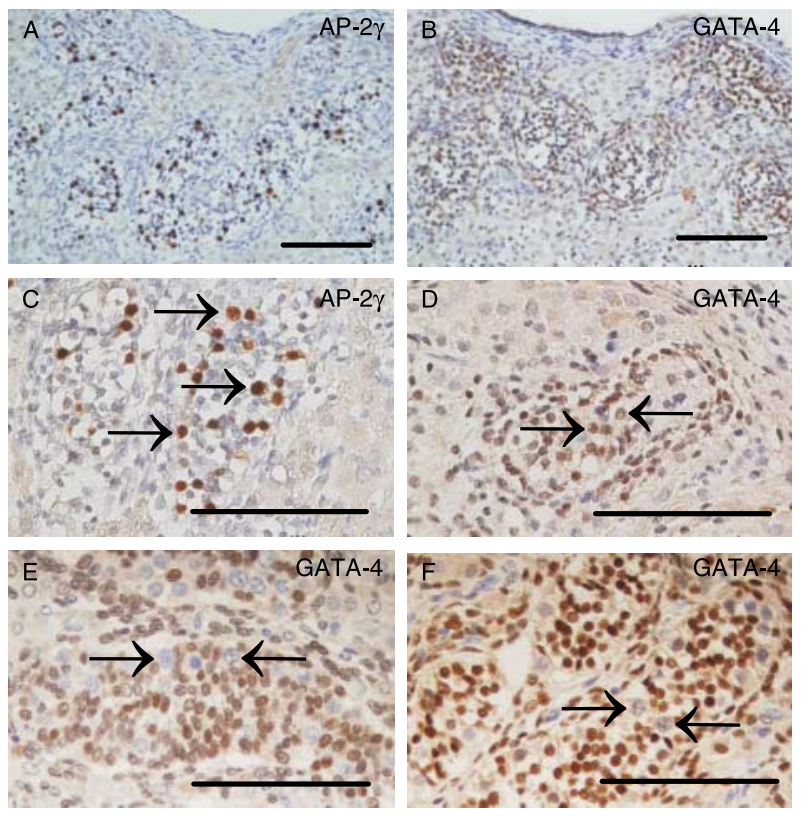

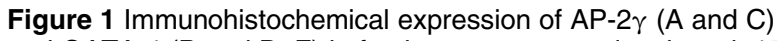
and GATA-4 (B and D-F) in fetal testes on gestational week 15 $(A-D), 17(E)$, and $20(F)$. Original magnification $\times 20(A$ and $B)$, $\times 40(\mathrm{C}-\mathrm{F})$. Scale bar $200 \mu \mathrm{m}$. Gonocytes are marked with arrows.

cytoplasm in contrast to the strong nuclear-only staining in Sertoli cells (Fig. 2B). FOG-2 expression was detected in most of the CIS cells, its expression being uniform in most of the samples. GATA-6 was expressed heterogeneously in most of the CIS cells. As to GATA-4 target genes, SF1 was heterogeneously expressed in most of the CIS cells, but INH $\alpha$ was mostly absent, and AMH totally negative in CIS cells of all samples.

Most of the seminomas expressed heterogeneously GATA-4 and GATA-6 (Fig. 3A and D, Table 1). Staining for FOG-2, AMH, SF1, and INH $\alpha$ was mostly negative. Non-seminoma tumors were mostly composed of different histological components, and yolk sac, choriocarcinoma, and embryonal carcinoma components within these tumors were identified by staining for AFP, human chorionic gonadotropin, and Oct-3/4 respectively. Of the non-seminomas, embryonal carcinomas and choriocarcinomas did not express GATA-4, FOG-2, GATA-6, SF-1, or INH- $\alpha$ (Fig. 3B, E and H, Table 1). In contrast, yolk sac tumors abundantly expressed GATA-4, GATA-6, and target gene SF-1, whereas they remained negative for the other studied GATA target genes AMH and INH $\alpha$ (Fig. 3C, F and I, Table 1). In addition, immature teratomas expressed GATA-4 and FOG-2, but not the other genes studied.

\section{Discussion}

In this study, we unequivocally demonstrated the expression of GATA-4 in a subpopulation of early human fetal germ cells. This finding is in line with our previous study suggesting GATA-4 expression in early fetal gonocytes from the 12th week of gestation (9). We confirmed in the current study that the GATA-4 positive cells are gonocytes by examining in parallel the expression of a gonocytes-specific marker, AP- $2 \gamma$ in serial sections. Like GATA-4 (this study), several proteins are downregulated in germ cells during the early fetal development, while early gonocytes differentiate to spermatogonia $(18,19)$. These proteins include pluripotency markers OCT-3/4 and NANOG, and AP- $2 \gamma$, the germ cell expression of which is declining gradually from the second trimester of gestation onwards $(16,20)$. GATA- 4 thus adds to the list of these early human gonocyte markers.

CIS cells are considered to be arrested and transformed gonocytes, but the details of the molecular pathophysiology of CIS are not well understood $(14,19)$. Surprisingly, in this study, we found that CIS cells expressed GATA-4. The possible role of GATA-4 in CIS remains unraveled, but it is noteworthy that enhanced GATA-4 expression has also been reported in other tumor types such as adrenal cortical carcinomas, and it has been speculated to serve as a survival factor for tumor cells (21). Interestingly, GATA-4 expression within a given sample was not uniform but rather heterogeneous, without any association with the histological type of the adjacent tumor. The significance of this finding remains unclear, but heterogeneous expression in CIS cells has also been reported for some other proteins, such as TRA-1-60, a marker of pluripotency (16). As to TRA-1-60, the heterogenous
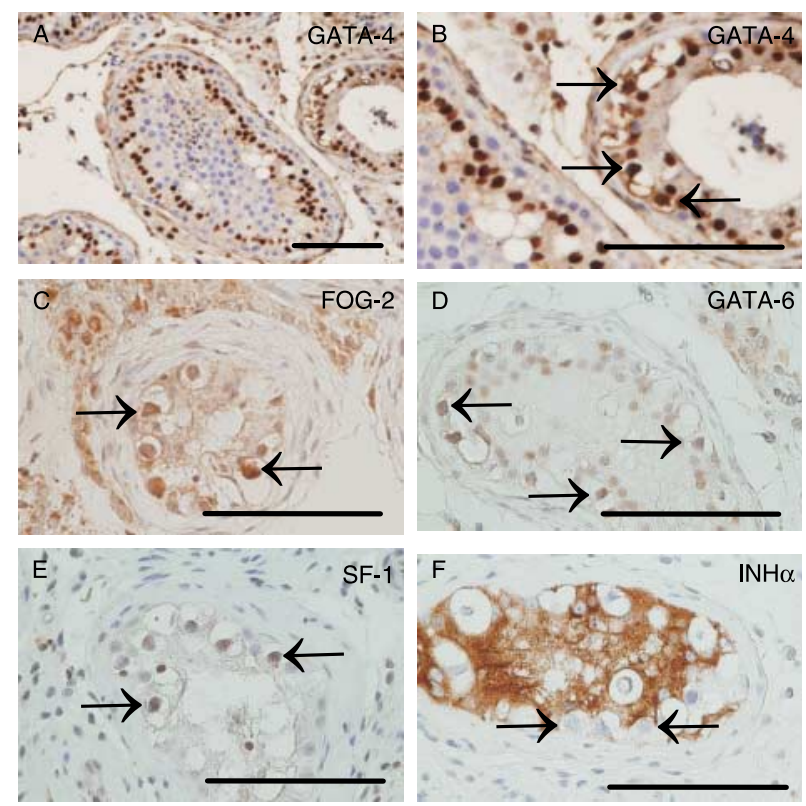

Figure 2 Immunohistochemical expression of GATA-4 (A and B), its coregulator FOG-2 (C), GATA-6 (D), and target genes SF-1 $(E)$ and INH $\alpha(F)$ in testes with CIS. Original magnification $\times 10(A)$, $\times 40(\mathrm{~B}-\mathrm{F})$. Scale bar $200 \mu \mathrm{m}$. CIS cells are marked with arrows. 

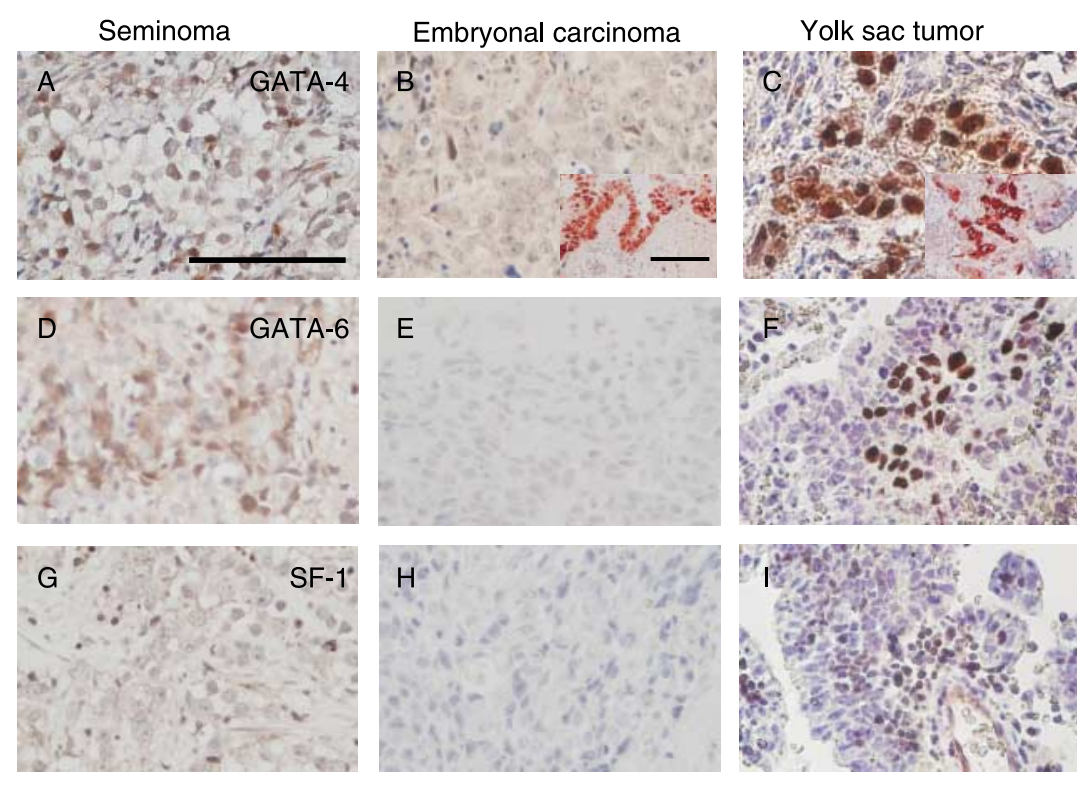

Figure 3 Immunohistochemical expression of GATA-4 (A-C), GATA-6 (D-F), SF-1 (G-I) in seminoma ( $A, D$ and $G)$, embryonal carcinoma (B, $E$ and $H)$, and yolk sac tumor (C, $\mathrm{F}$ and $\mathrm{I}$ ); embryonal carcinoma component is identified by its expression of Oct-3/4 (inset in $\mathrm{B}$ ), and yolk sac tumor component is identified by its expression of AFP (inset in C). Original magnification $\times 40$. Scale bar $200 \mu \mathrm{m}$. pattern is presumed to be linked to the progressive genomic aberrations or reprograming to lead to invasive tumors (22). In contrast to GATA-4 and TRA-1-60, pluripotency markers OCT3/4 and AP- $\gamma$ are homogenously expressed in CIS cells $(16,23)$.

GATA-4 is essential for testicular development and executes its functions together with its co-factor FOG-2 (5). In Fog $2^{-/-}$mice, Sry expression is reduced, and Sry downstream genes Sox 9 and Amh are downregulated. In our study, we investigated the expression of GATA-4 and its cofactor FOG-2 as well as a set of essential testicular target genes in CIS samples. Our finding of the simultaneous expression of the essential GATA-4 cofactor FOG-2 in most of the CIS cells suggests that GATA-4 can function to drive target gene expression in CIS cells. However, only one known GATA-4 target gene, $S F-1$, was also expressed in CIS cells, whereas other testicular GATA-4 targets, INH $\alpha$ and AMH were not present. Although it is not possible to draw definitive conclusions on the biological significance of these findings based on immunohistochemistry, the differential expression of the presumed GATA-4 target genes suggests distinct role of this transcription factor in CIS cells as compared to normal gonadal somatic cells.

We speculate that the expression of GATA-4 in a subset of CIS and seminoma cells reflects their gonocytelike phenotype. Gonocytes retain some features of embryonic stem cells, most notably a high expression of pluripotency-related genes, such as OCT3/4 and NANOG $(14,18,19)$. In this study, we demonstrated also the presence of GATA-4, which is a marker for early somatic differentiation of the inner cell mass (ICM) (24), in early gonocytes. We hypothesize that GATA-4 may be one of the genes upregulated during the germ cell specification from ICM. The absence of GATA-4 in embryonal carcinoma, which is a malignant equivalent of pluripotent embryonic stem cells that lost germ cell lineage characteristics, is in line with this hypothesis.

In the ovary, GATA- 4 is expressed in a subpopulation of dysgerminomas (75\%) (25), which is a tumor with a very close gene expression profile as compared to testicular seminomas (26). Here, we find that also most of the testicular seminomas are positive for GATA-4. Similarly to dysgerminomas (25), seminomas were mostly negative for the GATA-4 cofactor FOG-2, suggesting that GATA-4 may not function properly in seminoma tissue due to a lack of the presence of this essential cofactor. Although GATA-6 has not been detected in ovarian dysgerminomas (25), we now show that most of the testicular seminomas express this transcription factor. Taken together, although certain similarities between the corresponding ovarian and testicular tumors exist, there are also clear differences in their gene expression patterns. Thus, the role of GATA factors and their cofactors may differ in germ cell tumors in the male and female.

Within the non-seminoma group of testicular tumors, yolk sac tumor components abundantly expressed GATA-4 as well as GATA- 6 in contrast to their absence in embryonal carcinomas and choriocarcinomas. In line with this study, GATA-4 and GATA-6 expression has also been demonstrated in pediatric testicular as well as non-gonadal yolk sac tumors $(27,28)$. Moreover, GATA-4 expression has been reported in adult ovarian and testicular yolk sac tumors $(25,29)$.

Interestingly, GATA-4 appears to regulate different pathways in Sertoli cells before and after the onset of spermatogenesis. AMH, one of the presumed targets of GATA-4, is only expressed in immature Sertoli cells, 
whereas the expression of GATA-4 remains activated in adult testes. In adult testes harboring CIS cells, AMH was only expressed in some visibly undifferentiated Sertoli cells, which is a sign of testicular dysgenesis (30-32).

We herein demonstrate the expression of GATA-4 in a subpopulation of early fetal germ cells, presumably gonocytes, and its downregulation during differentiation of germ cells to spermatogonia. Reflecting this developmental pattern, GATA-4 is heterogeneously positive in CIS cells and seminomas, the germ cell neoplasms of adult testes that retain the immature gonocyte-like phenotype. In contrast, GATA-4 was not detectable in non-seminomas with embryonic features.

In conclusion, we find that GATA-4, GATA-6, and FOG-2 proteins are present in CIS cells, which concomitantly also express the GATA downstream target gene SF-1. The constellation of the GATA target genes between various testicular cell types does differ, as indicated by the abundance of AMH and INH $\alpha$ in Sertoli cells and their absence in CIS cells. The present findings also support the early fetal origin of CIS cells, and suggest that GATA-4 is involved in early germ cell differentiation.

\section{Declaration of interest}

The authors declare that there is no conflict of interest that could be perceived as prejudicing the impartiality of the research reported.

\section{Funding}

This work was supported by the Sigrid Jusélius Foundation, the Finnish Cancer Organizations, Academy of Finland, the Finnish Medical Society Duodecim, the National Clinical Graduate School, and the Danish Cancer Society.

\section{Acknowledgements}

We thank Dr Oskari Heikinheimo for critical reading of the manuscript, and Ms Taru Jokinen, Ms Sabina Soultanova, and Ms Lene Andersen for skilful technical assistance.

\section{References}

1 Bielinska M, Seehra A, Toppari J, Heikinheimo M \& Wilson DB. GATA-4 is required for sex steroidogenic cell development in the fetal mouse. Developmental Dynamics 2007236 203-213.

2 Ketola I, Rahman N, Toppari J, Bielinska M, Porter-Tinge SB, Tapanainen JS, Huhtaniemi IT, Wilson DB \& Heikinheimo M. Expression and regulation of transcription factors GATA-4 and GATA-6 in developing mouse testis. Endocrinology 1999140 $1470-1480$.

3 Tremblay JJ \& Viger RS. GATA factors differentially activate multiple gonadal promoters through conserved GATA regulatory elements. Endocrinology $2001 \mathbf{1 4 2}$ 977-986.

4 Viger RS, Guittot SM, Anttonen M, Wilson DB \& Heikinheimo M. Role of the GATA family of transcription factors in endocrine development, function, and disease. Molecular Endocrinology 2008 22 781-798.
5 Tevosian SG, Albrecht KH, Crispino JD, Fujiwara Y, Eicher EM \& Orkin SH. Gonadal differentiation, sex determination and normal Sry expression in mice require direct interaction between transcription partners GATA4 and FOG2. Development 2002129 4627-4634.

6 Manuylov NL, Fujiwara Y, Adameyko II, Poulat F \& Tevosian SG. The regulation of Sox 9 gene expression by the GATA4/FOG2 transcriptional complex in dominant $\mathrm{XX}$ sex reversal mouse models. Developmental Biology 2007307 356-367.

7 Tremblay JJ, Robert NM \& Viger RS. Modulation of endogenous GATA-4 activity reveals its dual contribution to Mullerian inhibiting substance gene transcription in Sertoli cells. Molecular Endocrinology 200115 1636-1650.

8 Anttonen M, Ketola I, Parviainen H, Pusa AK \& Heikinheimo M. FOG- 2 and GATA- 4 are coexpressed in the mouse ovary and can modulate Mullerian-inhibiting substance expression. Biology of Reproduction 200368 1333-1340.

9 Ketola I, Pentikainen V, Vaskivuo T, Ilvesmaki V, Herva R, Dunkel L, Tapanainen JS, Toppari J \& Heikinheimo M. Expression of transcription factor GATA-4 during human testicular development and disease. Journal of Clinical Endocrinology and Metabolism 200085 3925-3931.

10 Ketola I, Toppari J, Vaskivuo T, Herva R, Tapanainen JS \& Heikinheimo M. Transcription factor GATA-6, cell proliferation, apoptosis, and apoptosis-related proteins Bcl-2 and Bax in human fetal testis. Journal of Clinical Endocrinology and Metabolism 2003 88 1858-1865.

11 Robert NM, Tremblay JJ \& Viger RS. Friend of GATA (FOG)-1 and FOG-2 differentially repress the GATA-dependent activity of multiple gonadal promoters. Endocrinology $2002 \quad 143$ 3963-3973.

12 Ketola I, Anttonen M, Vaskivuo T, Tapanainen JS, Toppari J \& Heikinheimo M. Developmental expression and spermatogenic stage specificity of transcription factors GATA- 1 and GATA- 4 and their cofactors FOG-1 and FOG-2 in the mouse testis. European Journal of Endocrinology 2002147 397-406.

13 Skakkebaek NE, Berthelsen JG, Giwercman A \& Müller J. Carcinoma in situ of the testis: possible origin from gonocytes and precursor of all types of germ cell tumours except spermatocytoma. International Journal of Andrology $1987 \mathbf{1 0}$ 19-28.

14 Rajpert-De Meyts E \& Hoei-Hansen CE. From gonocytes to testicular cancer: the role of impaired gonadal development. Annals of the New York Academy of Sciences 20071120 168-180.

15 Oosterhuis JW \& Looijenga LH. Testicular germ-cell tumours in a broader perspective. Nature Reviews. Cancer 20055 210-222.

16 Hoei-Hansen CE, Nielsen JE, Almstrup K, Sonne SB, Graem N, Skakkebaek NE, Leffers H \& Rajpert-De Meyts E. Transcription factor AP- $2 \gamma$ is a developmentally regulated marker of testicular carcinoma in situ and germ cell tumors. Clinical Cancer Research 200410 8521-8530.

17 Lin L \& Achermann JC. Steroidogenic factor-1 (SF-1, Ad4BP, NR5A1) and disorders of testis development. Sexual Development 20082 200-209.

18 Honecker F, Stoop H, de Krijger RR, Lau YF, Bokemeyer C \& Looijenga LH. Pathobiological implications of the expression of markers of testicular carcinoma in situ by fetal germ cells. Journal of Pathology 2004203 849-857.

19 Rajpert-De Meyts E. Developmental model for the pathogenesis of testicular carcinoma in situ: genetic and environmental aspects. Human Reproduction Update 200612 303-323.

20 Rajpert-De Meyts E, Hanstein R, Jorgensen N, Graem N, Vogt PH \& Skakkebaek NE. Developmental expression of POU5F1 (OCT-3/4) in normal and dysgenetic human gonads. Human Reproduction $2004191338-1344$.

21 Kiiveri S, Siltanen S, Rahman N, Bielinska M, Lehto VP, Huhtaniemi IT, Muglia LJ, Wilson DB \& Heikinheimo M. Reciprocal changes in the expression of transcription factors GATA-4 and GATA- 6 accompany adrenocortical tumorigenesis in mice and humans. Molecular Medicine 19995 490-501. 
22 Almstrup K, Hoei-Hansen CE, Nielsen JE, Wirkner U, Ansorge W, Skakkebaek NE, Rajpert-De Meyts E \& Leffers H. Genome-wide gene expression profiling of testicular carcinoma in situ progression into overt tumours. British Journal of Cancer 200592 1934-1941.

23 de Jong J, Stoop H, Dohle GR, Bangma CH, Kliffen M, van Esser JV, van den Bent M, Kros JM, Oosterhuis JW \& Looijenga LH. Diagnostic value of OCT3/4 for pre-invasive and invasive testicular germ cell tumours. Journal of Pathology 2005206 242-249.

24 Fujikura J, Yamato E, Yonemura S, Hosoda K, Masui S, Nakao K, Miyazaki Ji J \& Niwa H. Differentiation of embryonic stem cells is induced by GATA factors. Genes and Development 200216 784-789.

25 Mannisto S, Butzow R, Salonen J, Leminen A, Heikinheimo O \& Heikinheimo M. Transcription factors GATA-4 and GATA-6, and their potential downstream effectors in ovarian germ cell tumors. Tumour Biology 200526 265-273.

26 Hoei-Hansen CE, Kraggerud SM, Abeler VM, Kaern J, Rajpert-De Meyts E \& Lothe RA. Ovarian dysgerminomas are characterised by frequent KIT mutations and abundant expression of pluripotency markers. Molecular Cancer 2007612.

27 Siltanen S, Anttonen M, Heikkila P, Narita N, Laitinen M, Ritvos O, Wilson DB \& Heikinheimo M. Transcription factor GATA-4 is expressed in pediatric yolk sac tumors. American Journal of Pathology 1999155 1823-1829.
28 Siltanen S, Heikkila P, Bielinska M, Wilson DB \& Heikinheimo M. Transcription factor GATA-6 is expressed in malignant endoderm of pediatric yolk sac tumors and in teratomas. Pediatric Research $200354542-546$.

29 Looijenga LH. Human testicular (non)seminomatous germ cell tumours: the clinical implications of recent pathobiological insights. Journal of Pathology 2009218 146-162.

30 Steger K, Rey R, Louis F, Kliesch S, Behre HM, Nieschlag E, Hoepffner W, Bailey D, Marks A \& Bergmann M. Reversion of the differentiated phenotype and maturation block in Sertoli cells in pathological human testis. Human Reproduction 199914 136-143.

31 Rajpert-De Meyts E, Jorgensen N, Graem N, Muller J, Cate RL \& Skakkebaek NE. Expression of anti-Mullerian hormone during normal and pathological gonadal development: association with differentiation of Sertoli and granulosa cells. Journal of Clinical Endocrinology and Metabolism 199984 3836-3844.

32 Schreiber L, Lifschitz-Mercer B, Paz G, Yavetz H, Zadik Z, Kula K, Slowikowska-Hilczer J, Rey R, Elliott DJ \& Maymon BB. Lack of RBM expression as a marker for carcinoma in situ of prepubertal dysgenetic testis. Journal of Andrology 200324 78-84.

Received 17 November 2009

Accepted 27 November 2009 